\title{
Alternatives to mental health admissions for children and adolescents experiencing mental health crises: A systematic review of the literature
}

\author{
Denisa A Clisu ${ }^{1,2}{ }^{\circ}$, Imogen Layther ${ }^{3}$, Deborah Dover ${ }^{2}$, \\ Russell M Viner', Tina Read ${ }^{2}$, David Cheesman', Sally Hodges ${ }^{4}$ and \\ Lee D Hudson 1,3 \\ 'UCL GOS Institute of Child Health, London, UK; \\ ${ }^{2}$ Barnet Enfield and Haringey Mental Health Trust, London, UK; \\ ${ }^{3}$ Great Ormond Street Hospital, London, UK; \\ ${ }^{4}$ The Tavistock and Portman NHS Trust, London, UK
}

\begin{abstract}
Background: Many children and young people (CYP) presenting with mental health crises are admitted to hospital due to concerns around illness severity and risk. Whilst inpatient admissions have an important role for such children, there are a number of burdens associated with them, and safe avoidance of admissions is favourable. We systematically reviewed the literature for studies of interventions reported as alternatives to a hospital admission in CYP presenting with mental health crises, in any inpatient setting. Methods: Three databases (Psychlnfo, PubMed and Web of Science) were searched for peer-reviewed papers in October 2020, with an updated search in May 2021. Results: We identified 19 papers of interventions delivered in the emergency department, the home, outside of home but outside of clinics and in hospital clinics. The quality of most included studies was low, with less than half being randomised controlled trials and only half of these at low risk of bias. The best quality studies and greatest evidence for efficacy came from in-home interventions, in particular multisystemic therapy, which improved psychological outcomes, and though a large number of CYP still ended up being admitted, there appeared to be decreased length of stay. Conclusions: Overall, we could not recommend a particular intervention as an alternative to inpatient admission; however, our review describes benefits across a range of types of interventions that might be considered in multi-modal treatments. We also provide recommendations for future research, in particular the evaluation of new interventions as they emerge.
\end{abstract}

\section{Corresponding author:}

Denisa A Clisu, Department of Population, Policy and Practice, UCL Great Ormond Street UCL Great Ormond Institute for Child Health, 30 Guilford Street, London WCIN IEH, UK.

Email: d.clisu.16@ucl.ac.uk 


\section{Keywords}

Child, adolescent, mental health, inpatient admissions, crisis

\section{Background}

Mental health disorders are a substantial burden for children and young people's (CYP) health globally (Polanczyk et al., 2015), with suicide a leading cause of death (Wasserman et al., 2005). In the UK, recent data have shown that $16 \%$ of CYP have a mental health disorder, with over half of older adolescents with a disorder having self-harmed or attempted suicide (Vizard et al., 2020). Similar prevalence rates have been reported in Europe and the United States (Kovess-Masfety et al., 2016; Merikangas et al., 2010). Though these are longstanding issues, the recent COVID-19 pandemic appears to have worsened the mental health for some children (Ford et al., 2021). Many CYP with mental health disorders will present to health care providers with an acute (sometimes called psychiatric) crisis due to their mental health. Such crises can be defined as subjective experiences where a change in mental wellbeing occurs, and the person becomes unstable or at risk to themselves or others (Jennings \& Child, 2017). In high income countries, numbers of such presentations for CYP seemed to have increased, both to secondary and primary care (Mahajan et al., 2009; Morgan et al., 2017; Newton et al., 2009; Pittsenbarger \& Mannix, 2014). Severity of illness, concern about risk (especially in relation to suicide) (Hawton et al., 2012), available community services (Lancet, 2020) and social circumstances (Paranjothy et al., 2018) may mean that such presentations result in an inpatient admission. Whilst hospitalisation rates for most paediatric conditions in high income countries have decreased in recent years, admissions because of mental health have increased (Torio et al., 2015).

Inpatient mental health admissions can provide important and vital services for significantly unwell CYP (Green et al., 2007), for example more intensive levels of care and the opportunity for longer, good quality, therapeutic relationships with inpatient staff (Sergent, 2009). However, they can also carry substantial burden. Mental health admissions can be lengthy, in locations away from a usual place of residence, leading to disconnection from friends and family and separation from education or employment. These burdens are especially amplified for CYP experiencing repeated admissions (Miller et al., 2020). Inpatient mental health admissions are also more costly for health care systems (Green et al., 2007) versus outpatient care. Demand can also outstrip capacity (O'Herlihy et al., 2003), resulting in admissions of CYP in adult psychiatric wards or non-mental health inpatient settings such as paediatric medical wards (Worrall et al., 2004). Safe and effective interventions acting as alternatives to inpatient admissions for CYP presenting in crisis are therefore highly favourable. Policy makers have turned attention on to this issue, for example in the UK there are strategies in place to improve community services (Alderwick \& Dixon, 2019).

Developing and implementing alternatives to inpatient mental health admissions for CYP presenting in crisis requires an up-to-date synthesis of the literature. Previous systematic reviews on this topic (Kwok et al., 2016; Shepperd et al., 2009) are now outdated (with the latest literature search performed in 2014) and also included papers of interventions with an admission component (such as short-term hospitalisations) which could be a confounder for the effects of proposed alternatives. We therefore systematically reviewed the literature for studies of interventions reported as alternatives to a mental health admission in CYP presenting with a significant mental health crisis, in any inpatient setting. We specifically examined for:

1. effectiveness at avoiding admission or any impact on reducing the length of an inpatient stay if one followed. 
2. Improvements in psychological parameters for CYP secondary to such interventions.

\section{Methods}

We searched three databases: PsychInfo, PubMed and Web of Science in October 2020, with an updated search in May 2021. We used search terms to encompass 'children and young people', 'mental health crisis' and 'potential locations of care' (Supplementary Appendix A). Searches were conducted individually by two researchers (DC and IL) who selected abstracts for inclusion or exclusion. Papers were then downloaded and considered independently, with LH providing adjudication. Reference lists within studies were also screened.

We included studies reporting outcomes of interventions specifically as alternatives to a mental health admission for CYP presenting with a mental health crisis. We defined admission as any hospitalisation in any inpatient setting (including general medical settings). We excluded (1) studies where some or all participants were > 18 years; (2) studies not published in English; (3) reviews; (4) papers which did not provide any outcome measures or insufficient outcome measures, or only described interventions; (4) studies where the intervention included an admission.

Independent bias assessments were conducted by DC and IL using the Cochrane Review tools for assessing risk of bias in randomised trials (RCTs) (Sterne et al., 2019) and non-RCT (Sterne et al., 2016). Discrepancies were discussed for agreement with final adjudication by LH.

\section{Results}

We found 782 papers in initial searches of databases and were left with 640 unique studies after duplicate removal. Seventy-one papers were retrieved, with 60 excluded based on full text assessment. We found an additional 8 studies from screening reference lists. We included a total of 19 studies. A summary of the search with numbers is shown in Figure 1.

Eight studies were RCTs, 4 studies were service evaluations, 4 studies used an uncontrolled prepost-treatment investigation, 2 papers used pre-intervention historical/retrospective control groups and 1 paper used a matched control group. Fourteen studies were conducted in the USA, 2 were conducted in Germany, 2 in Canada and 1 in the UK. Two studies reported on interventions specifically for CYP with suicidal risk, 1 for psychosis and 1 for disruptive behaviour/externalising crisis presentations and 15 were for mixed types of crisis mental health presentations. For RCTs, we found 4 papers at low risk of bias, 2 raising some concerns and 2 at high risk of bias, and for nonRCTs, we found 1 paper at low risk of bias, 2 papers at moderate risk, 6 papers at serious risk of bias and 2 papers at critical risk. Detailed summaries of included studies, including bias assessment are shown in Table 1. Detailed rationale for classifying final bias category for each study is shown in Supplementary Appendix B.

Included papers did not allow sufficiently robust information to perform meta-analysis, and so, we present findings here narratively, with interventions grouped by: (1) Single-session interventions for emergency department crisis presentations and (2) Community-based crisis interventions (as (i) exclusively in-home interventions, (ii) interventions outside of the home but outside clinics and (iii) exclusively clinic-based outpatient interventions, including intensive day treatment).

\section{Single-session interventions for emergency department crisis presentations}

We found three papers which evaluated the effectiveness of single-session urgent response consultations in emergency departments. Two papers were service evaluations (Gillig, 2004; Parker 


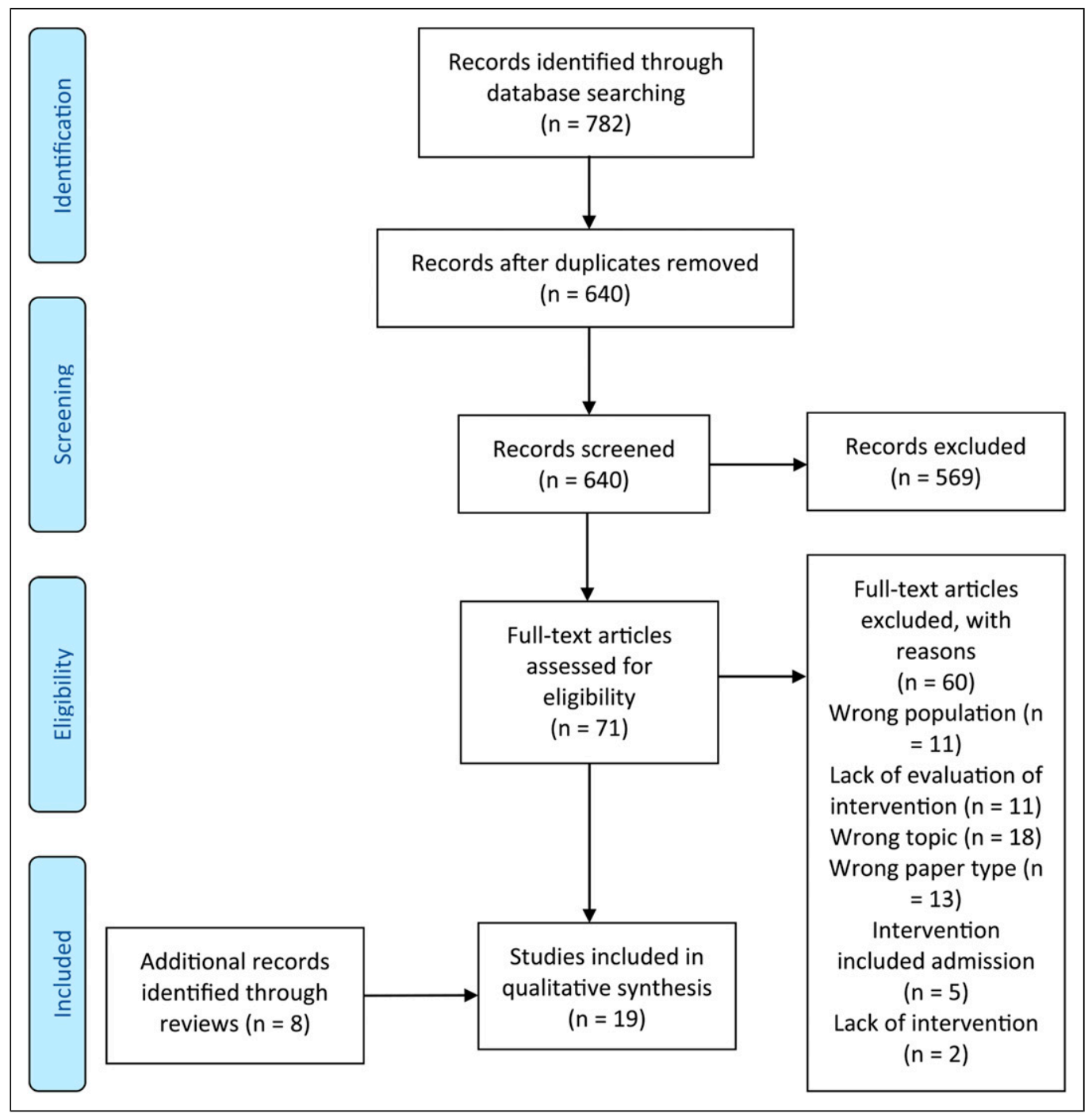

Figure I. PRISMA flow diagram of included and excluded studies.

et al., 2003), and one paper used a pre-intervention historical/retrospective control group (Wharff et al., 2012). One paper was at critical risk of bias (Gillig, 2004), one at serious risk of bias (Parker et al., 2003) and one at low risk of bias (Wharff et al., 2012). Gillig (2004) investigated the effects of offering an emergency evaluation interview and a brief therapeutic intervention at a maximum of 24 hours after CYP presentation, using a supportive, reality-based and present-focused therapeutic approach. They reported that only $10 \%(n=5)$ of the patients seen by the emergency consultation team were hospitalised right after the input was received, no patients were hospitalised in the month following the input and 4.2\% $(n=2)$ patients were hospitalised 6 months later. Parker et al. (2003) analysed a Rapid Response Model (RRM) which offered consultations to CYP in acute mental health crises within 48 hours of their presentation to the ED, focussing on the crisis and risk. They 


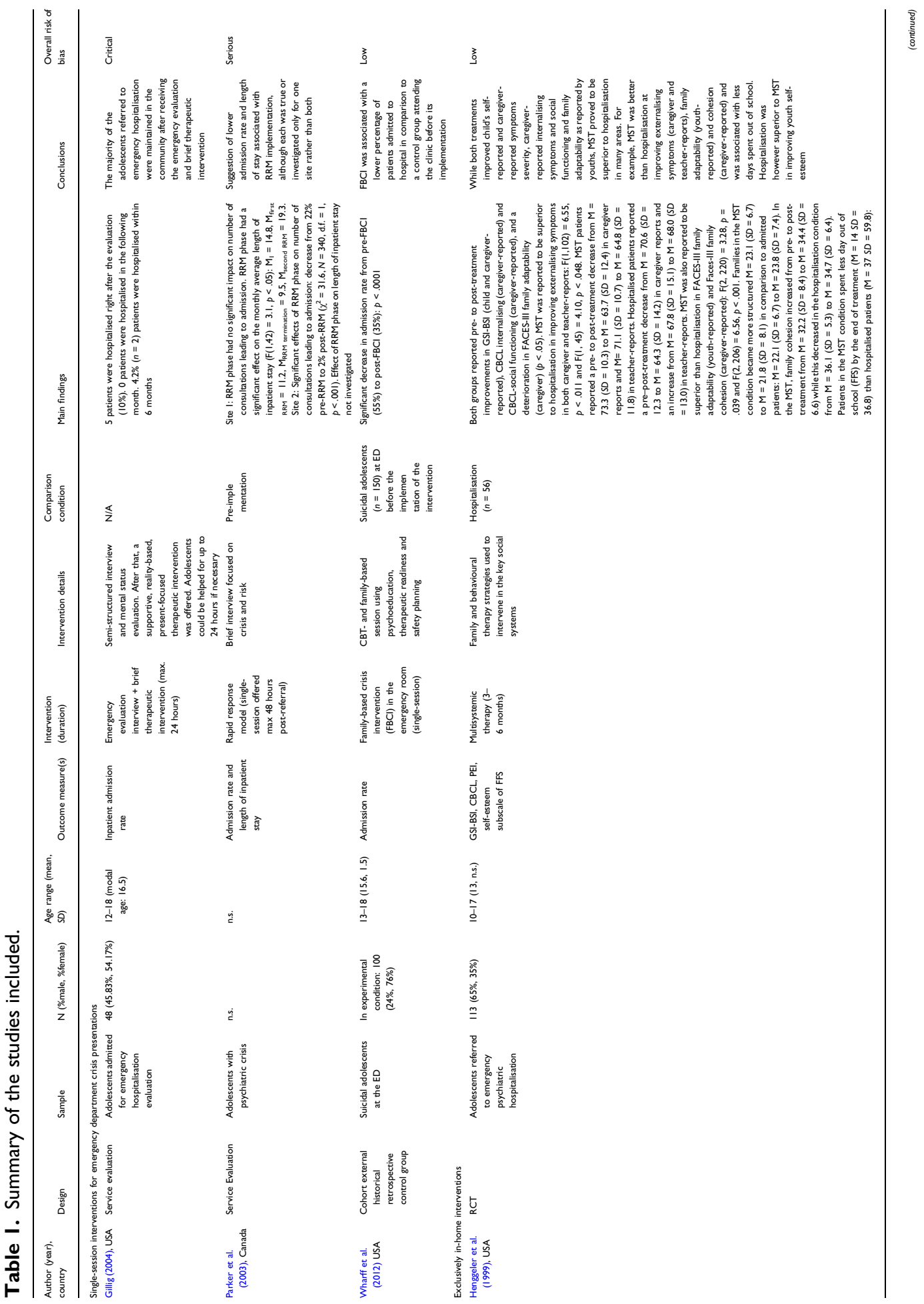




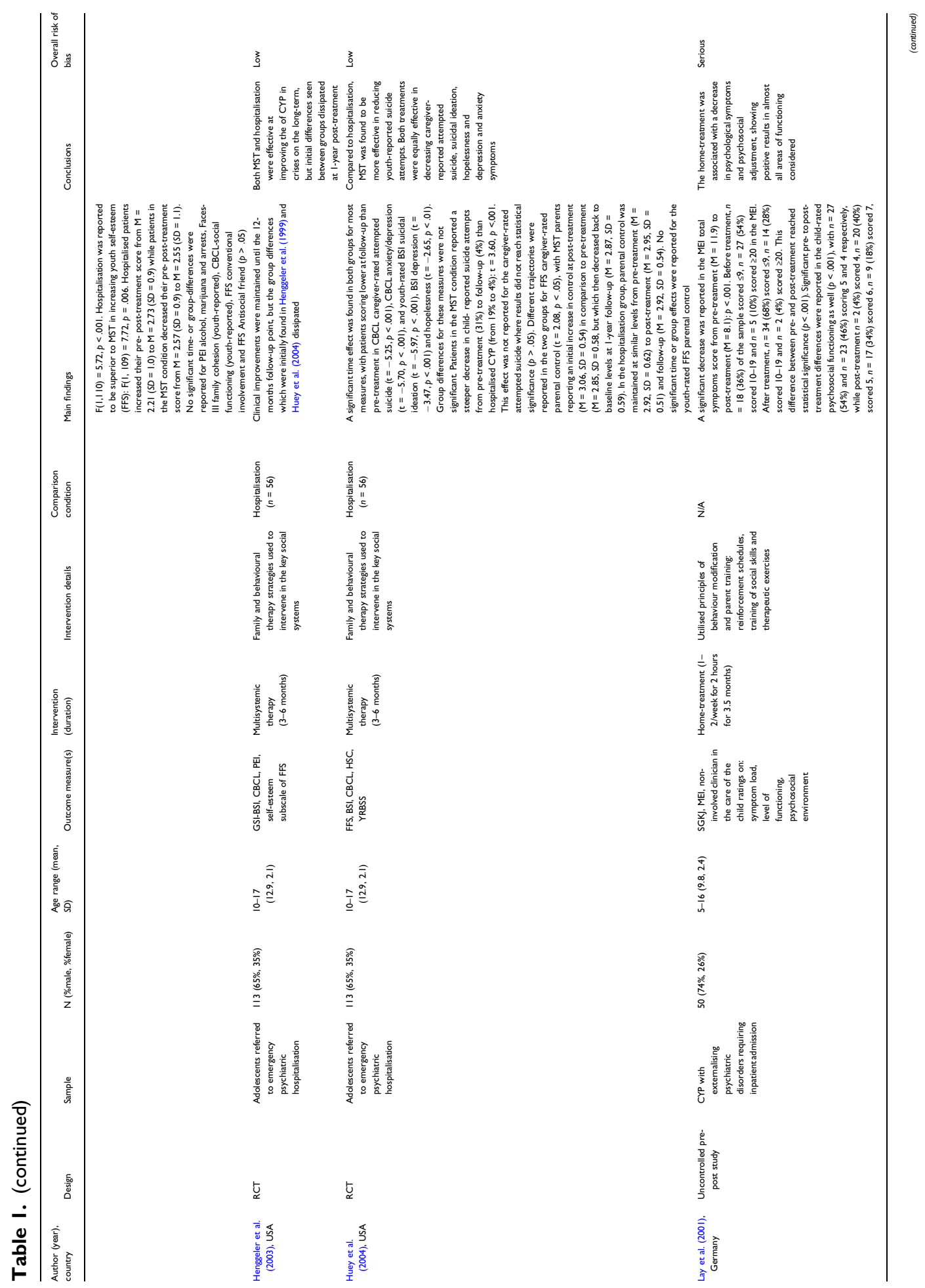




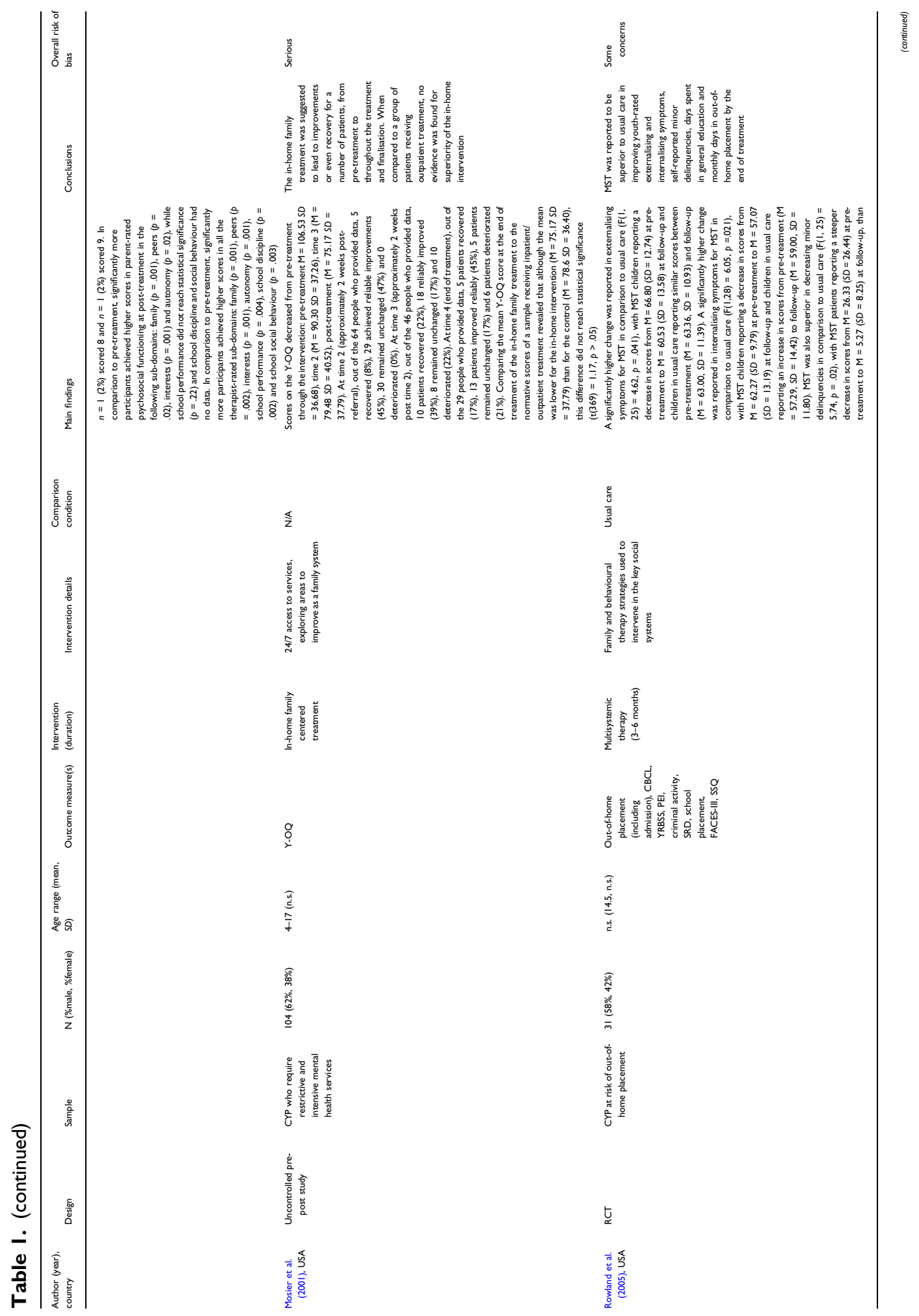




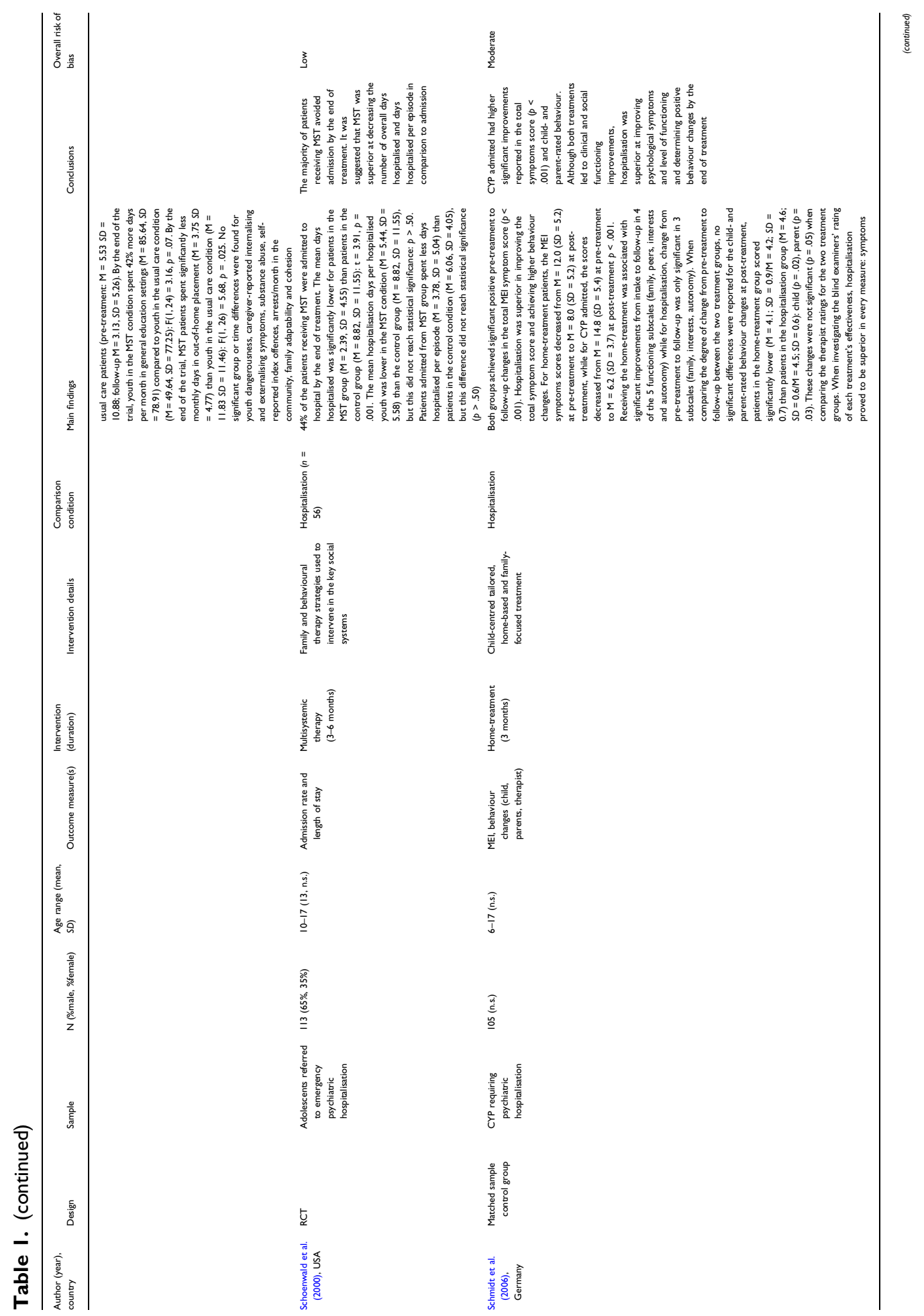




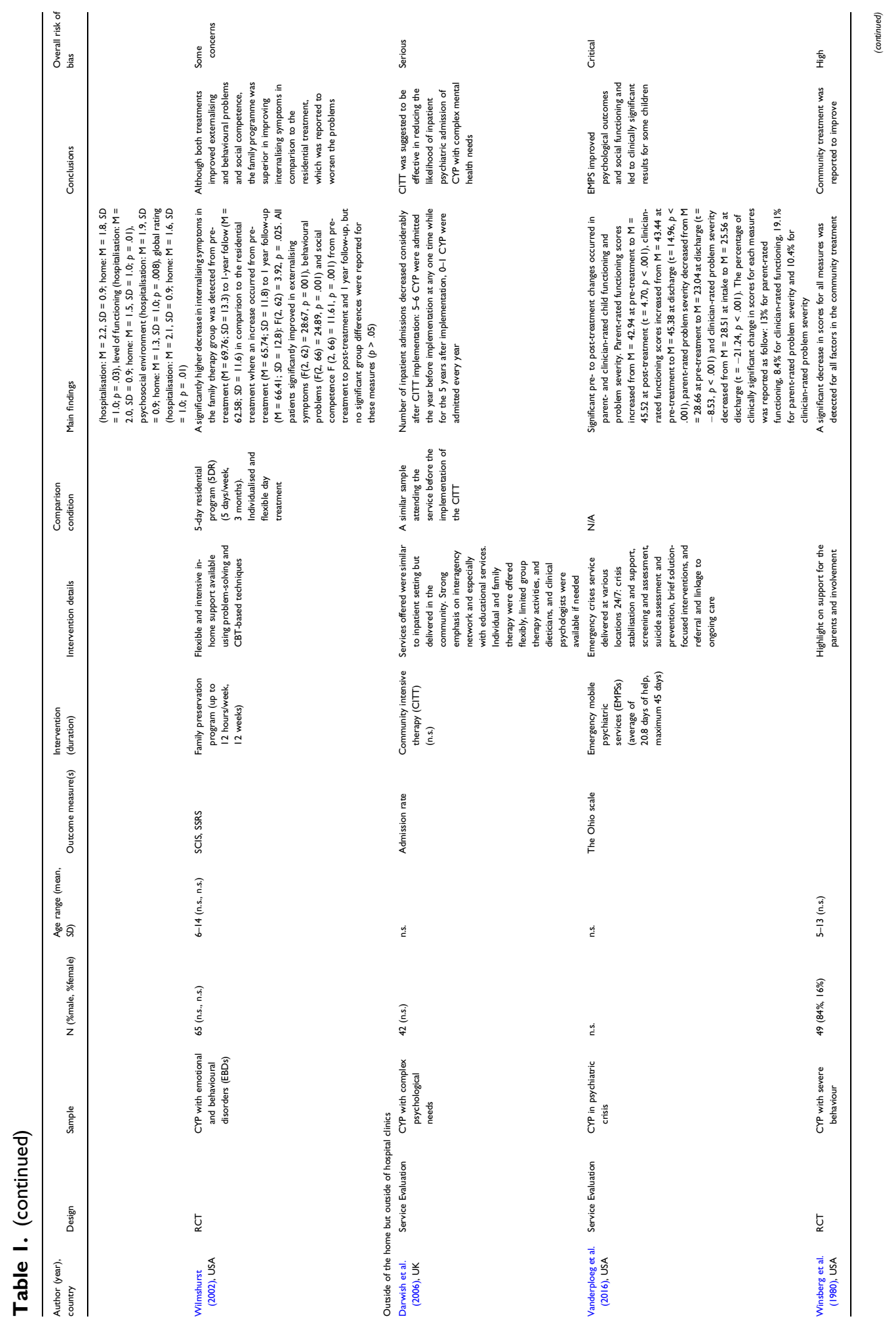




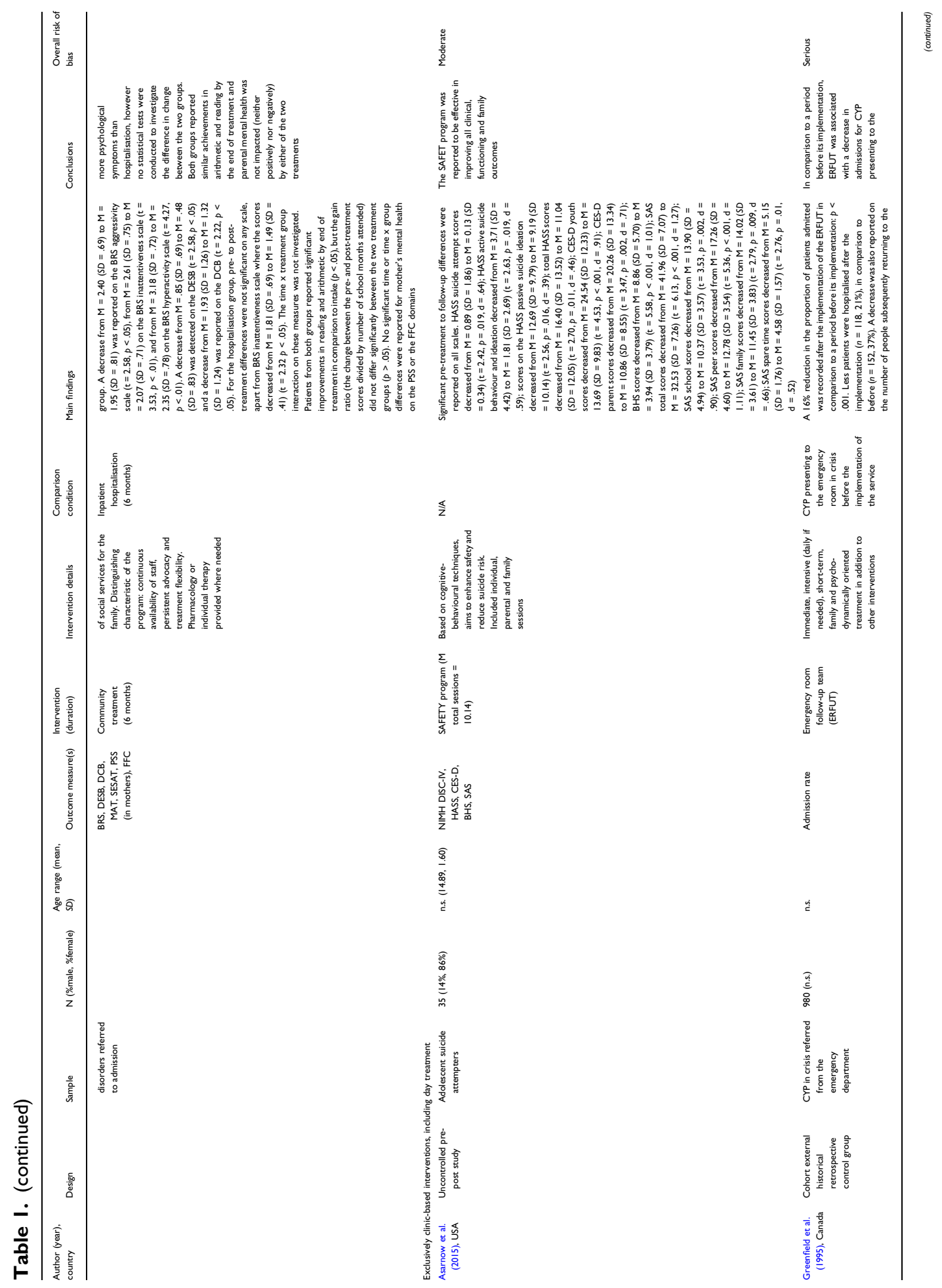




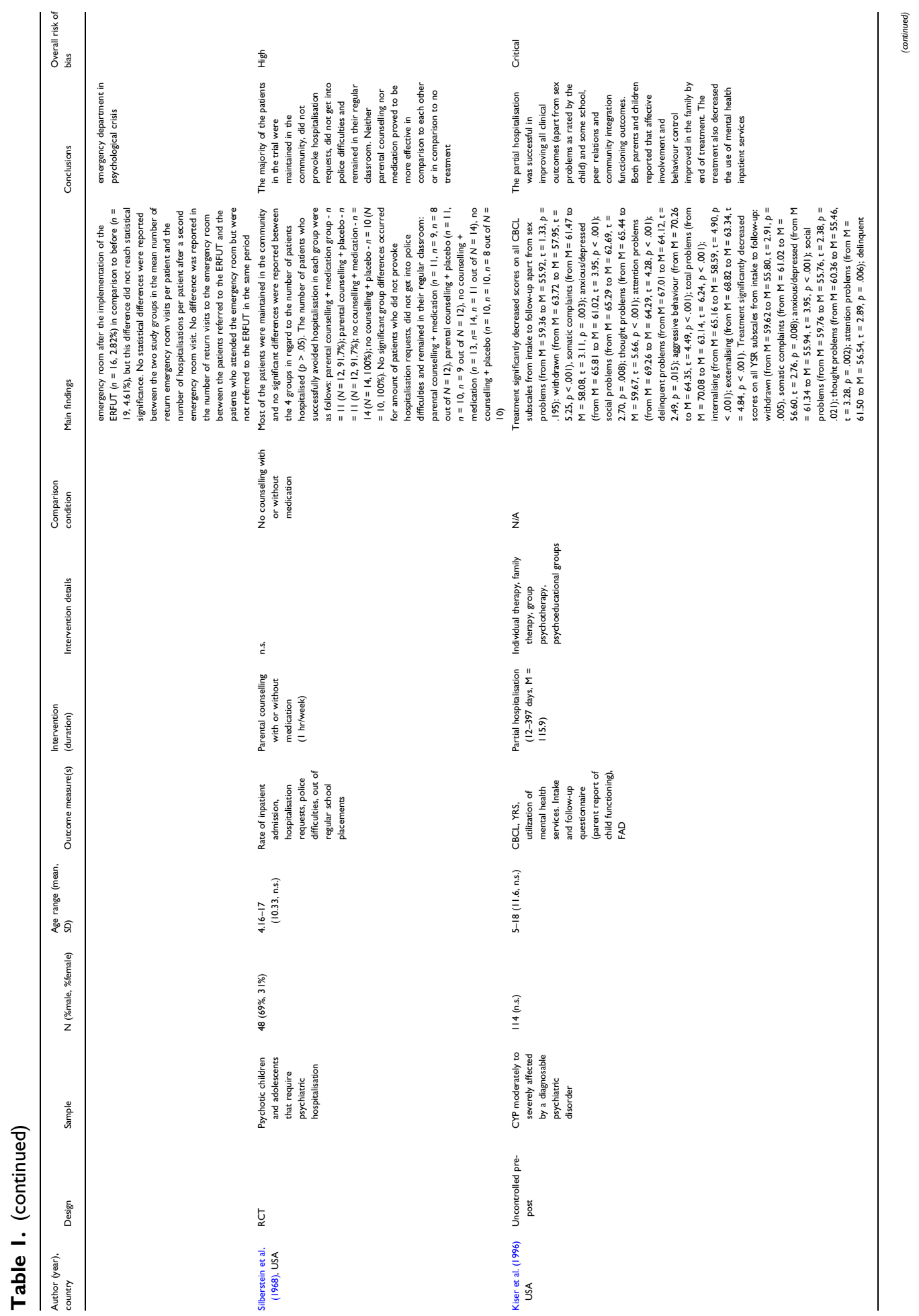




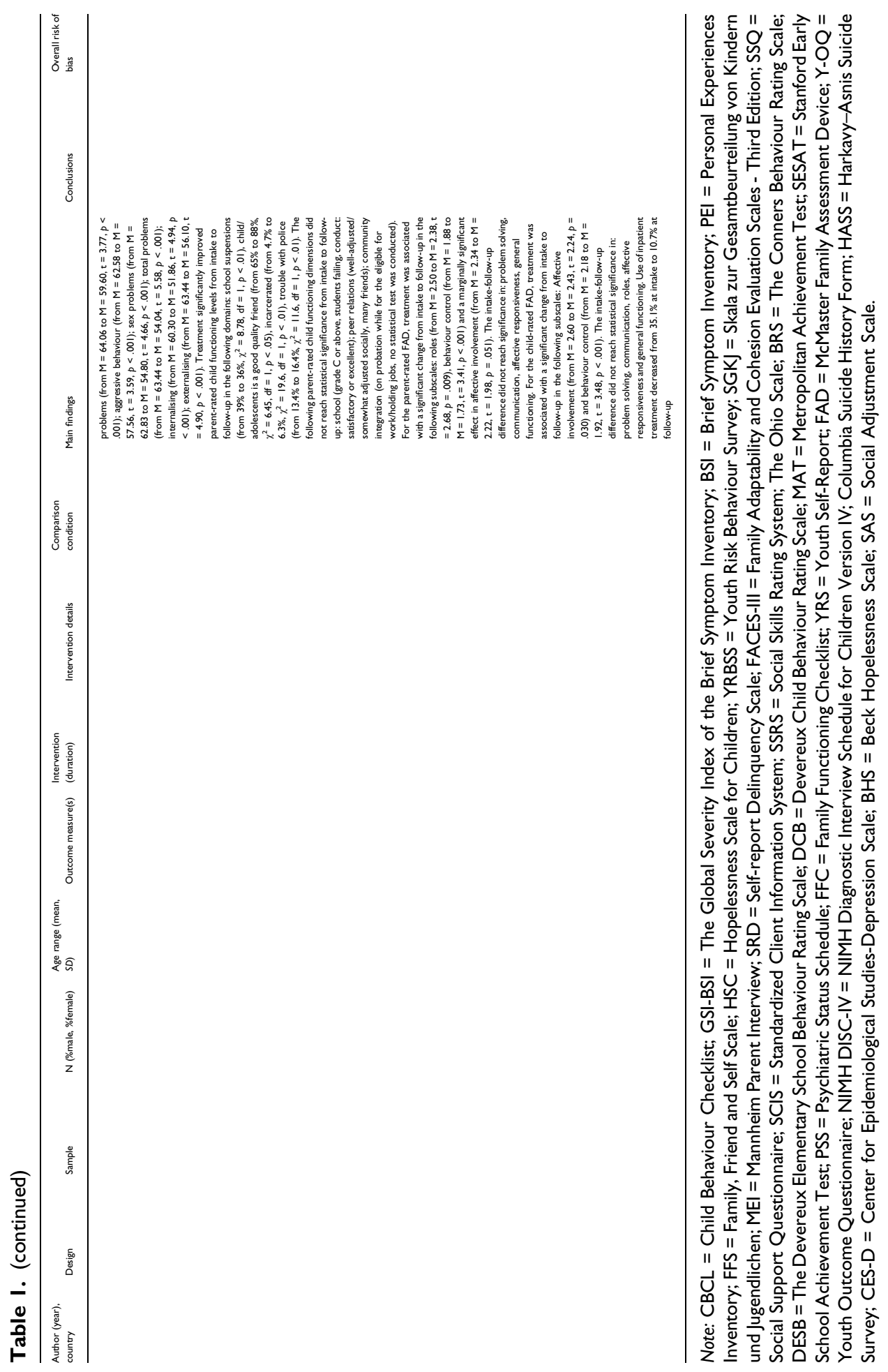


used two sites: one site studied outcomes over 4 years (with pre-RRM, during RRM implementation, post-RRM termination and during RRM re-implementation as four time periods) and another over 2 years (pre-RRM and post-RRM as two time periods). Findings were mixed. For the first site, no change was reported in the number of admissions over the four time periods but RRM stage had a significant effect on the monthly average length of inpatient stay: $F(1,42)=3.1, p<.05)$. For the second site, there was a reported decrease in the percentage of admissions, with a reduction from $22 \%$ at pre-RRM to $2 \%$ at post-RRM $\left(\chi^{2}=31.6, N=340\right.$, d.f. $\left.=1, p<.001\right)$. Wharff et al. (2012) investigated a single-session family-based crisis intervention (FBCI) for suicidal adolescents, delivered in a paediatric ED and focussing on constructing a safety plan and encouraging family communication. They reported a reduction in numbers admitted during the implementation of FBCI $(55 \%-35 \%, p<.0001)$.

\section{Community-based treatments}

We found fourteen papers investigating the effectiveness of community-based treatments for CYP presenting in crisis. Nine were of home interventions, three were community interventions outside of the home but outside clinics and two were exclusively clinic-based outpatient interventions, including day treatment.

Exclusively in-home interventions. We found nine papers studying in-home interventions - five studying multisystemic therapy (MST) and four papers of other family-based interventions in the home.

Five papers investigated the effectiveness of multisystemic therapy (MST) delivered at home and which combined a range of therapeutic approaches. All five papers were RCTs, although four were in effect different outcomes from one single trial (Henggeler et al., 1999, 2003; Huey et al., 2004; Schoenwald et al., 2000). The risk of bias assessment revealed that four papers were at low risk of bias (Henggeler et al., 1999, 2003; Huey et al., 2004; Rowland et al., 2005; Schoenwald et al., 2000) while one raised some concerns (Rowland et al., 2005).

The effects of MST on admission rates and length of stay were investigated by two papers in two separate trials (Rowland et al., 2005; Schoenwald et al., 2000). In one RCT, in a sample of CYP in mental health crisis assessed to require an admission, MST was compared to hospitalisation (Schoenwald et al., 2000). At the end of treatment, 44\% of those assigned to the MST group (approximately 4 months post-referral) were admitted to hospital and mean length of stay was lower than the hospitalised control group (mean days 2.39 vs. $8.82, t=3.91, p=.001$ ). In a second RCT, CYP at risk of out-of-home placement (e.g. inpatient hospitalisation, group homes and foster care) were randomly assigned to receive either MST or usual care (Rowland et al., 2005). The study did not report on the number of patients hospitalised following the intervention in either group. However, number of days spent in out-of-home placement per month were lower in the intervention group (mean days 3.75 vs. $11.83, F=5.68, p=.025$ ).

Potential psychological benefits of MST were investigated in four papers, three reporting outcomes from a single trial comparing MST to inpatients, and one from another trial comparing MST to usual care. Compared to hospitalisation (Henggeler et al., 1999; Huey et al., 2004), MST was reported to have superiority in improving a number of psychological measures. Postintervention changes were superior compared to admission controls for the caregiver-rated externalising symptoms $(F(1,102)=6.55, p<.011)$, teacher rated externalising symptoms $(F(1,45)=$ $4.10, p<.048)$, youth-reported family adaptability $(F(2,220)=3.28, p=.039)$, caregiver-rated family cohesion $(F(2,206)=6.56, p<.001)$ and youth-reported suicide attempts $(t=3.60, p<.001)$. 
However, a further paper of 12-16 month follow-up revealed that generally superiority was not sustained (Henggeler et al., 2003). Change in self-esteem was initially superior in the hospitalised group $(F(1,109)=7.72, p=.006)$; however, again this was not sustained at 12-16-month follow-up. For MST compared to treatment as usual (Rowland et al., 2005), there was superior change in youthrated externalising symptoms $(F(1,25)=4.62, p=.041)$ and internalising symptoms $(F(1,28)=$ $6.05, p=.021)$ for the MST group.

We found four papers of other family-based interventions delivered at home which reported on psychological outcomes. One was an RCT (Wilmshurst, 2002), one was a study using a matched sample control group (Schmidt et al., 2006) and two were uncontrolled studies investigating pre- to post-treatment changes (Lay et al., 2001; Mosier et al., 2001). Bias assessment revealed that two papers were at serious risk of bias (Lay et al., 2001; Mosier et al., 2001), one paper was at moderate risk (Schmidt et al., 2006) while the other paper raised some concerns (Wilmshurst, 2002). Neither paper described proportions of CYP receiving the alternative interventions who required admission. In the RCT, Wilmshurst (2002) reported that the in-home treatment was superior to a 5-day residential programme in improving internalising symptoms at follow-up $(F(2,62)=3.92$ and $p=$ .025). Comparing the intervention to a matched control group receiving hospitalisation, Schmidt et al. (2006) reported that by the end of treatment, hospitalisation was superior at improving psychological symptoms related to major DSM-IV diagnoses $(p<.001)$, child-rated behaviour $(p=$ $.02)$, parent-rated behaviour $(p=.03)$ and increased functioning in more domains (family, peers, interests and autonomy) than the in-home treatment (family, interests and autonomy). Lay et al. (2001) compared pre- and post-treatment outcomes in a sample of CYP requiring an intervention as an alternative to admission presenting with high risk externalising behaviours. Improvements were reported in the total symptoms related to major DSM-IV diagnoses $(p<.001)$ and child-rated psychosocial functioning $(p<.001)$. Mosier et al. (2001) also compared pre- and post-treatment outcomes of an in-home famility therapy for CYP requiring restrictive and intensive mental health treatment. In comparison to pre-treatment, post-treatment improvements were reported in clinical symptoms for a number of CYP, with some being reported to have recovered. No statistical tests were conducted for this comparison. The end of treatment mean clinical symptoms of the group was compared to the normative scores of patients receiving inpatient/outpatient treatment, but no significant differences were reported.

Interventions outside of the home but outside of hospital clinics. We found three papers which evaluated the effectiveness of community interventions outside of the home but away from clinic settings. The stated aim of these interventions was to stabilize the patients by offering an array of services, delivered flexibly in the community depending on need (e.g. schools). One paper was an RCT (Winsberg et al., 1980) and two papers were service evaluations (Darwish et al., 2006; Vanderploeg et al., 2016). The risk of bias assessment revealed that one paper was at high risk of bias (Winsberg et al., 1980), one was at critical risk (Vanderploeg et al., 2016) and one was at serious risk (Darwish et al., 2006). Only one of these papers, Darwish et al. (2006), reported on admission outcomes for their intervention, reporting that their community intensive therapy decreased admissions compared to a pre-intervention historical group (decreasing to one person per year over 5 years versus six people per year at pre-implementation, no statistics presented). Two papers reported on psychological outcomes. Winsberg et al. (1980) reported pre- and post-intervention scales and hospitalisation on a group of CYP in crisis, on a range of psychological parameters. Post-intervention, the community treatment improved symptoms of aggression $(t=2.58, p<.05)$, inattentiveness $(t=3.53$, $p<.01)$, hyperactivity $(t=4.27, p<.01)$, school behaviour $(t=2.58, p<.05)$, and overall child behaviour $(t=2.22, p<.05)$. In comparison, hospitalisation improved only inattentiveness $(t=2.32$ 
$p<.05)$. There was however no comparison of differences between the interventions and hospitalised groups. Vanderploeg et al. (2016) studied changes in a sample of CYP receiving emergency mobile psychiatric services however they did not compare their outcomes to a control group. They reported that improvements were achieved in parent-rated problem severity $(t=-8.53$, $p<.001)$, clinician-rated problem severity $(t=-21.24, p<.001)$ parent-rated child functioning $(t=$ $4.70, p<.001)$ and clinician-rated child functioning $(t=14.96, p<.001)$.

Exclusively clinic-based interventions, including intensive day treatment. We found four papers which evaluated the effects of interventions in clinic-based settings (one including intensive day treatment) in CYP presenting in crisis as alternatives to hospitalisation. One paper was an RCT (Silberstein et al., 1968), one paper used a matched sample control group (Greenfield et al., 1995) and two papers were uncontrolled pre-post-intervention studies (Asarnow et al., 2015; Kiser et al., 1996). The risk of bias assessment revealed that one paper was at moderate risk of bias (Asarnow et al., 2015), one at high risk of bias (Silberstein et al., 1968), one at serious risk of bias (Greenfield et al., 1995) and one at critical risk (Kiser et al., 1996).

Silberstein et al. (1968) compared 4 separate groups of CYP presenting with psychosis receiving: (1) parental counselling with or (2) without medication; (3) no counselling plus medication; and (4) no counselling plus placebo. There were no differences in rates of admissions between groups. Greenfield et al. (1995) investigated the outcomes of implementing an emergency room follow-up team and reported that in comparison to a period before its implementation, the admission rate of CYP presenting to the emergency room in psychiatric crisis decreased by $16 \%(p<.001)$. No statistical difference was reported between the two groups in the number of hospitalisations occurring per patient after a second emergency room visit.

Kiser et al. (1996) reported on psychological outcomes of an outpatient day program for CYP in mental health crisis as an alternative to admission. Post-intervention, improvements were reported in being withdrawn (parent report: $t=5.25, p<.001$; CYP report: $t=2.91, p=.005$ ), somatic complaints (parent report: $t=3.11, p=.003$; CYP report: $t=2.76, p=.008$ ), anxious/depressed (parent report: $t=3.95, p<.001$; CYP report: $t=3.95, p<.001$ ), social problems (parent report: $t=$ $2.70, p=.008$; CYP report: $t=2.38, p=.021$ ), thought problems (parent report: $t=5.66, p<.001$; CYP report: $t=3.28, p=.002$ ), attention problems (parent report: $t=4.28, p<.001$; CYP report: $t=$ $2.89, p=.06$ ), delinquent behaviour (parent report: $t=32.49, p=.015$; CYP report: $t=3.77, p<$ .001 ), aggressive behaviour (parent report: $t=4.49, p<.001$; CYP report $t=3.59, p<.001$ ); sex problems (significant for CYP report only: $t=4.66, p<.001$ ), total problems (parent report: $t=6.24$, $p<.001$; CYP report $t=5.58, p<.001$ ), internalising (parent report: $t=4.90, p<.001$; CYP report: $t$ $=4.94, p<.001$ ) and externalising (parent report: $t=4.84, p<.001$; CYP report $t=4.90, p<.001$ ). Both parents and CYP also reported that at follow-up, family functioning was improved in the following domains: roles (parent report only: $t=2.68, p=.009$ ), affective involvement (CYP report only: $t=2.24, p=.03$ ) and behaviour control (parent report: $t=3.41, p=.001$; CYP report: $t=3.48$, $p=.001$ ). Follow-up improvements were also reported in rates of school suspensions (from $39 \%$ to $36 \%, \chi^{2}=8.78, \mathrm{df}=1, p<.01$ ) and CYP being a good quality friend (from $65 \%$ to $88 \%, \chi^{2}=6.45, \mathrm{df}$ $=1, p<.05)$, while a deterioration occurred in the CYP's legal status, with increased incarceration rates (from $4.7 \%$ to $6.3 \%, \chi^{2}=19.6, \mathrm{df}=1, p<.01$ ) and more trouble with the police at follow-up (from $13.4 \%$ to $16.4 \%, \chi^{2}=11.6, \mathrm{df}=1, p<.01$ ). Asarnow et al. (2015) reported on psychological outcomes of an outpatient intervention (the SAFETY program) delivered to adolescent suicide attempters. They reported pre- to post-treatment improvements in all outcomes measured: suicide attempts $(t=2.42, p=.019, d=.64)$, active suicide behaviour and ideation $(t=2.63, p=.019, d=$ $.59)$, passive suicide ideation $(t=2.56, p=.016, d=.39)$, total suicidality score $(t=2.70, p=.011, d$ 
$=.46)$, CYP reported youth depression symptoms $(t=4.53, p<.001, d=.91)$, parent-reported parental depression symptoms $(t=3.47, p=.002, d=.71)$, hopelessness $(t=5.58, p<.001, d=$ $1.01)$, social adjustment total score $(t=6.13, p<.001, d=1.27)$, social adjustment at school $(t=$ $3.53, p=.002, d=.90)$, social adjustment with peers $(t=5.36, p<.001, d=1.11)$, social adjustment with the family $(t=2.79, p=.009, d=.66)$ and social adjustment in the spare time $(t=2.76, p=.01$, $d=.52$ ).

\section{Discussion}

In this systematic review of studies of alternatives to inpatient admissions for CYP presenting with a mental health crisis, we found a range of published studies on interventions in different settings. We found studies describing interventions in emergency departments, the home, other community settings and hospital-based clinics. In general, the level of evidence was poor with less than half of included studies RCTs, of which only half were considered of low risk of bias in bias assessments. Studies also varied with regard to consistency of reporting on measures on preventing admissions and psychological outcomes. This meant that robust data for meta-analysis was insufficient. The greatest level of evidence came from home-treatments, in particular MST. The studies we found for MST offered treatment for 3-6 months and used family and behavioural therapy techniques to address the strengths and weaknesses of the CYP and their environment (i.e. family, peers and school) in a highly individualised treatment plan. MST was reported as improving a range of psychological parameters associated with risk for CYP (such as suicide attempts) and benefits for families (adaptation and cohesion though not maintained at 4 months); and though a large proportion of CYP appeared to still ultimately be admitted (in one study 44\%), there was evidence that length of stay from these admissions was reduced compared to admission alone. We found some evidence suggesting that brief emergency department-based interventions could have a beneficial impact on admission rates. These interventions consisted of either a single treatment session or support over a short period of time (i.e. 24 hours), and used either brief interviews to understand the crisis and risk, or cognitive-behavioural and family therapy techniques for psychoeducation, therapeutic readiness and safety planning. However, none of these studies were RCTs, and there was no information on impact upon psychological parameters in any paper. Evidence for other community interventions, and clinic-based interventions were scarce, and generally of low quality. However, we found some evidence for reduction in admission rates and improvements in postintervention symptom severity, child and family functioning, although these were not compared to outcomes of control groups.

Our review did not find sufficient amount of quality data to recommend a specific type of intervention for CYP presenting in crisis, a similar conclusion to the two other systematic reviews on this topic which included searches from over 6 years ago (Kwok et al., 2016; Shepperd et al., 2009). However, the evidence we have presented provides useful information for the development of new and existing services, including the potential for mix-models of care, or 'menus' of care for individual patients' needs by understanding variable benefits of different models. Given the challenges associated with the complexity of such CYP presenting in crisis, especially with regard to risk, the limited availability of good quality data is perhaps understandable. However, with such presentations increasing, and pressure on inpatient units rising (Children's Commissioner, 2020), this is clearly an area which needs to see an increase in research as a priority. With new emphasis on improvement for CYP with mental health disorders, especially those presenting in crisis (Ougrin et al., 2018), it is likely that new models will develop. It is important that as they do so, they are robustly evaluated, in particular with comparison to controls (including for example pre- 
intervention controls), with consistent measurement and reporting of success at reducing absolute numbers of admissions, duration of admissions and also psychological impacts for CYP and families. Studies should also report detail on change between groups of intervention and control, for a large proportion of studies we found in our review presented only pre and post values for intervention and control separately, and this impedes the opportunity for an appropriate pooling of studies in meta-analysis (Higgins et al., 2017).

Beyond the limitations which we have highlighted above, our review has a number of strengths. We used an a priori search strategy of multiple databases, with defined inclusion and exclusion criteria for the studies and two independent researchers performed searches. We also investigated on a large range of intervention types by also including non-RCTs, in comparison to previous reviews that looked at RCTs only. We reported on all outcomes described and had two independent researchers to conduct thorough bias assessments, with a third providing final adjudication.

In conclusion, although we found a range of interventions in different settings, the quality of studies was insufficient to allow for an overall recommendation. Interventions using multisystemic therapy at home had the best quality, with evidence suggesting benefits around avoiding admissions, length of admission and psychological outcomes. However, these interventions generally failed to show long-term effects. New models of care should be robustly evaluated using consistent outcomes.

\section{Declaration of conflicting interests}

The author(s) declared no potential conflicts of interest with respect to the research, authorship, and/or publication of this article.

\section{Funding}

The author(s) disclosed receipt of the following financial support for the research, authorship, and/or publication of this article: This article is supported by Great Ormond Street Hospital Charity.

\section{ORCID iDs}

Denisa A Clisu (D) https://orcid.org/0000-0002-7636-616X

Lee D Hudson (D) https://orcid.org/0000-0003-0883-8791

\section{Supplemental material}

Supplemental material for this article is available online.

\section{References}

Alderwick, H., \& Dixon, J. (2019). The NHS long term plan. British Medical Journal (Clinical Research ed.), 364(184), 184.

Asarnow, J. R., Berk, M., Hughes, J. L., \& Anderson, N. L. (2015). The SAFETY program: A treatmentdevelopment trial of a cognitive-behavioral family treatment for adolescent suicide attempters. Journal of Clinical Child \& Adolescent Psychology, 44(1), 194-203.

Children's Commissioner (2020). Who are they? Where are they? 2020. Children in Tier 4 Mental Health Units. Technical report.

Darwish, A., Salmon, G., Ahuja, A., \& Steed, L. (2006). The community intensive therapy team: Development and philosophy of a new service. Clinical Child Psychology and Psychiatry, 11(4), 591-605. 
Ford, T., John, A., \& Gunnell, D. (2021). Mental health of children and young people during pandemic. British Medical Journal Publishing Group, 372, n614.

Gillig, P. M. (2004). Child \& adolescent psychiatry: An adolescent crisis service in a rural area. Psychiatric Services, 55(12), 1363-1365.

Greenfield, B., Hechtman, L., \& Tremblay, C. (1995). Short-term efficacy of interventions by a youth crisis team. The Canadian Journal of Psychiatry, 40(6), 320-324.

Green, J., Jacobs, B., Beecham, J., Dunn, G., Kroll, L., Tobias, C., \& Briskman, J. (2007). Inpatient treatment in child and adolescent psychiatry-a prospective study of health gain and costs. Journal of Child Psychology and Psychiatry, 48(12), 1259-1267.

Hawton, K., Bergen, H., Kapur, N., Cooper, J., Steeg, S., Ness, J., \& Waters, K. (2012). Repetition of self-harm and suicide following self-harm in children and adolescents: Findings from the multicentre study of selfharm in England. Journal of Child Psychology and Psychiatry, 53(12), 1212-1219.

Henggeler, S. W., Rowland, M. D., Halliday-boykins, C., Sheidow, A. J., Ward, D. M., Randall, J., Pickrel, S. G., Cunningham, P. B., \& Edwards, J. (2003). One-year follow-up of multisystemic therapy as an alternative to the hospitalisation of youths in psychiatric crisis. Journal of the American Academy of Child \& Adolescent Psychiatry, 42(5), 543-551.

Henggeler, S. W., Rowland, M. D., Randall, J., Ward, D. M., Pickrel, S. G., Cunningham, P. B., Miller, S. L., Edwards, J., Zealberg, J. J., Hand, L. D., \& Santos, A. B. (1999). Home-based multisystemic therapy as an alternative to the hospitalisation of youths in psychiatric crisis: Clinical outcomes. Journal of the American Academy of Child \& Adolescent Psychiatry, 38(11), 1331-1339.

Higgins, J., Churchill, R., Chandler, J., \& Cumpston, M. (2017). Cochrane handbook for systematic reviews of interventions version 5.2.0. Cochrane (updated February 2017), 2017. Available from Cochrane Community.

Huey, S. J., Henggeler, S. W., Rowland, M. D., Halliday-Boykins, C. A., Cunningham, P. B., Pickrel, S. G., \& Edwards, J. (2004). Multisystemic therapy effects on attempted suicide by youths presenting psychiatric emergencies. Journal of the American Academy of Child \& Adolescent Psychiatry, 43(2), 183-190.

Jennings, S., \& Child, C. A. P. B. (2017). Healthy London partnership-children and young people programme: Improving care for children and young people in mental health crisis in London: Recommendations for transformation of services.

Kiser, L. J., Millsap, P. A., Hickerson, S., Heston, J. D., Nunn, W., Pruitt, D. B., \& Rohr, M. (1996). Results of treatment one year later: Child and adolescent partial hospitalisation. Journal of the American Academy of Child \& Adolescent Psychiatry, 35(1), 81-90.

Kovess-Masfety, V., Husky, M. M., Keyes, K., Hamilton, A., Pez, O., Bitfoi, A., Carta, M. G., Goelitz, D., Kuijpers, R., Otten, R., Koç, C., Lesinskiene, S., \& Mihova, Z. (2016). Comparing the prevalence of mental health problems in children 6-11 across Europe. Social Psychiatry and Psychiatric Epidemiology, 51(8), 1093-1103.

Kwok, K. H. R., Yuan, S. N. V., \& Ougrin, D. (2016). Review: Alternatives to inpatient care for children and adolescents with mental health disorders. Child and Adolescent Mental Health, 21(1), 3-10.

Lancet (2020). Child mental health services in England: A continuing crisis. Lancet, 395(10222), 389.

Lay, B., Blanz, B., \& Schmidt, M. H. (2001). Effectiveness of home treatment in children and adolescents with externalising psychiatric disorders. European Child \& Adolescent Psychiatry, 10(Suppl 1), I80-I90.

Mahajan, P., Alpern, E. R., Grupp-Phelan, J., Chamberlain, J., Dong, L., Holubkov, R., Jacobs, E., Stanley, R., Tunik, M., Sonnett, M., Miller, S., \& Foltin, G. L. (2009). Epidemiology of psychiatric-related visits to emergency departments in a multicentre collaborative research pediatric network. Pediatric Emergency Care, 25(11), 715-720.

Merikangas, K. R., He, J.-p., Burstein, M., Swanson, S. A., Avenevoli, S., Cui, L., Benjet, C., Georgiades, K., \& Swendsen, J. (2010). Lifetime prevalence of mental disorders in U.S. adolescents: Results from the 
National comorbidity survey replication-adolescent supplement (NCS-A). Journal of the American Academy of Child \& Adolescent Psychiatry, 49(10), 980-989.

Miller, D. A. A., Ronis, S. T., Slaunwhite, A. K., Audas, R., Richard, J., Tilleczek, K., \& Zhang, M. (2020). Longitudinal examination of youth readmission to mental health inpatient units. Child and Adolescent Mental Health, 25(4), 238-248.

Morgan, C., Webb, R. T., Carr, M. J., Kontopantelis, E., Green, J., Chew-Graham, C. A., Kapur, N., \& Ashcroft, D. M. (2017). Incidence, clinical management, and mortality risk following self harm among children and adolescents: Cohort study in primary care. British Medical Journal (Clinical Research ed.), 359, j4351.

Mosier, J., Burlingame, G. M., Wells, M. G., Ferre, R., Latkowski, M., Johansen, J., Peterson, G., \& Walton, E. (2001). In-Home, family-centered psychiatric treatment for high-risk children and youth. Children's Services, 4(2), 51-68.

Newton, A. S., Ali, S., Johnson, D. W., Haines, C., Rosychuk, R. J., Keaschuk, R. A., Jacobs, P., \& Klassen, T. P. (2009). A 4-year review of pediatric mental health emergencies in Alberta. Canadian Journal of Emergency Medicine, 11(5), 447-454.

O'Herlihy, A., Worrall, A., Lelliott, P., Jaffa, T., Hill, P., \& Banerjee, S. (2003). Distribution and characteristics of in-patient child and adolescent mental health services in England and Wales. British Journal of Psychiatry, 183(6), 547-551.

Ougrin, D., Corrigall, R., Poole, J., Zundel, T., Sarhane, M., Slater, V., Stahl, D., Reavey, P., Byford, S., Heslin, M., Ivens, J., Crommelin, M., Abdulla, Z., Hayes, D., Middleton, K., Nnadi, B., \& Taylor, E. (2018). Comparison of effectiveness and cost-effectiveness of an intensive community supported discharge service versus treatment as usual for adolescents with psychiatric emergencies: A randomised controlled trial. Lancet Psychiatry, 5(6), 477-485.

Paranjothy, S., Evans, A., Bandyopadhyay, A., Fone, D., Schofield, B., John, A., Bellis, M. A., Lyons, R. A., Farewell, D., \& Long, S. J. (2018). Risk of emergency hospital admission in children associated with mental disorders and alcohol misuse in the household: An electronic birth cohort study. Lancet Public Health, 3(6), e279-e288.

Parker, K. C. H., Roberts, N., Williams, C., Benjamin, M., Cripps, L., \& Woogh, C. (2003). Urgent adolescent psychiatric consultation: From the accident and emergency department to inpatient adolescent psychiatry. Journal of Adolescence, 26(3), 283-293.

Pittsenbarger, Z. E. \& Mannix, R. (2014). Trends in pediatric visits to the emergency department for psychiatric illnesses. Academic Emergency Medicine, 21(1), 25-30.

Polanczyk, G. V., Salum, G. A., Sugaya, L. S., Caye, A., \& Rohde, L. A. (2015). Annual research review: A meta-analysis of the worldwide prevalence of mental disorders in children and adolescents. Journal of Child Psychology and Psychiatry, 56(3), 345-365.

Rowland, M. D., Halliday-Boykins, C. A., Henggeler, S. W., Cunningham, P. B., Lee, T. G., Kruesi, M. J. P., \& Shapiro, S. B. (2005). A randomized trial of multisystemic therapy with Hawaii's Felix class youths. Journal of Emotional and Behavioral Disorders, 13(1), 13-23.

Schmidt, M. H., Lay, B., Göpel, C., Naab, S., \& Blanz, B. (2006). Home treatment for children and adolescents with psychiatric disorders. European Child \& Adolescent Psychiatry, 15(5), 265-276.

Schoenwald, S. K., Ward, D. M., Henggeler, S. W., \& Rowland, M. D. (2000). Multisystemic therapy versus hospitalisation for crisis stabilisation of youth: Placement outcomes 4 months postreferral. Mental Health Services Research, 2(1), 3-12.

Sergent, A. (2009). Sergent A. (2010) National Workforce Programme Child and Adolescent Mental Health National CAMHS Mental Health. Working Within Child and Adolescent Mental Health Inpatient Services. A Practitioner's Handbook. 
Shepperd, S., Doll, H., Gowers, S., James, A., Fazel, M., Fitzpatrick, R., \& Pollock, J. (2009). Alternatives to inpatient mental health care for children and young people. The Cochrane Database of Systematic Reviews, 15(2), CD006410.

Silberstein, R. M., Mandell, W., Dalack, J. D., \& Cooper, A. (1968). Avoiding institutionalisation of psychotic children. Archives of General Psychiatry, 19(1), 17-21.

Sterne, J. A., Hernán, M. A., Reeves, B. C., Savović, J., Berkman, N. D., Viswanathan, M., Henry, D., Altman, D. G., Ansari, M. T., Boutron, I., Carpenter, J. R., Chan, A.-W., Churchill, R., Deeks, J. J., Hróbjartsson, A., Kirkham, J., Jüni, P., Loke, Y. K., Pigott, T. D., \& Higgins, J. P. (2016). ROBINS-I: A tool for assessing risk of bias in non-randomised studies of interventions. British Medical Journal, 355, i4919.

Sterne, J. A. C., Savović, J., Page, M. J., Elbers, R. G., Blencowe, N. S., Boutron, I., Cates, C. J., Cheng, H. Y., Corbett, M. S., Eldridge, S. M., Emberson, J. R., Hernán, M. A., Hopewell, S., Hróbjartsson, A., Junqueira, D. R., Jüni, P., Kirkham, J. J., Lasserson, T., Li, T., \& Higgins, J. P. T. (2019). RoB 2: A revised tool for assessing risk of bias in randomised trials. British Medical Journal (Clinical Research ed.), 366, 14898.

Torio, C. M., Encinosa, W., Berdahl, T., McCormick, M. C., \& Simpson, L. A. (2015). Annual report on health care for children and youth in the United States: National estimates of cost, utilisation and expenditures for children with mental health conditions. Academic Pediatrics, 15(1), 19-35.

Vanderploeg, J. J., Lu, J. J., Marshall, T. M., \& Stevens, K. (2016). Mobile crisis services for children and families: Advancing a community-based model in connecticut. Children and Youth Services Review, 71, 103-109.

Vizard, T., Sadler, K., \& Ford, T. (2020). Mental health of children and young people in England, 2020: Wave 1 follow up to the 2017 survey. NHS Digital. https:/digital.nhs.uk/data-and-information/publications/ statistical/mental-health-of-children-and-young-people-in-england/2020-wave-1-follow-up.

Wasserman, D., Cheng, Q., \& Jiang, G. X. (2005). Global suicide rates among young people aged 15-19. World Psychiatry: Official Journal of the World Psychiatric Association (WPA), 4(2), 114-120.

Wharff, E. A., Ginnis, K. M., \& Ross, A. M. (2012). Family-based crisis intervention with suicidal adolescents in the emergency room: A pilot study. Social Work, 57(2), 133-143.

Wilmshurst, L. A. (2002). Treatment programs for youth with emotional and behavioural disorders: An outcome study of two alternate approaches. Mental Health Services Research, 4(2), 85-96.

Winsberg, B. G., Bialer, I., Kupietz, S., Botti, E., \& Balka, E. B. (1980). Home vs hospital care of children with behavior disorders. Archives of General Psychiatry, 37(4), 413-418.

Worrall, A., O’Herlihy, A., Banerjee, S., Jaffa, T., Lelliott, P., Hill, P., Scott, A., \& Brook, H. (2004). Inappropriate admission of young people with mental disorder to adult psychiatric wards and paediatric wards: Cross sectional study of six months' activity. British Medical Journal, 328(7444), 867.

\section{Appendix A}

Search terms used for all databases: [(children and adolescents OR children OR adolescents OR youth) AND mental health AND (crisis OR crises)] AND [emergency department OR a\&e OR 'alternatives to hospital admission' OR 'home treatment' OR 'community based crisis' OR 'alternative care' OR 'short stay hospital' OR 'acute day hospital' OR 'acute ward' OR 'crisis houses' OR 'family based treatment' OR 'multisystemic therapy' OR 'crash pad*' NOT (homeless OR homelessness)].

\section{Appendix B}




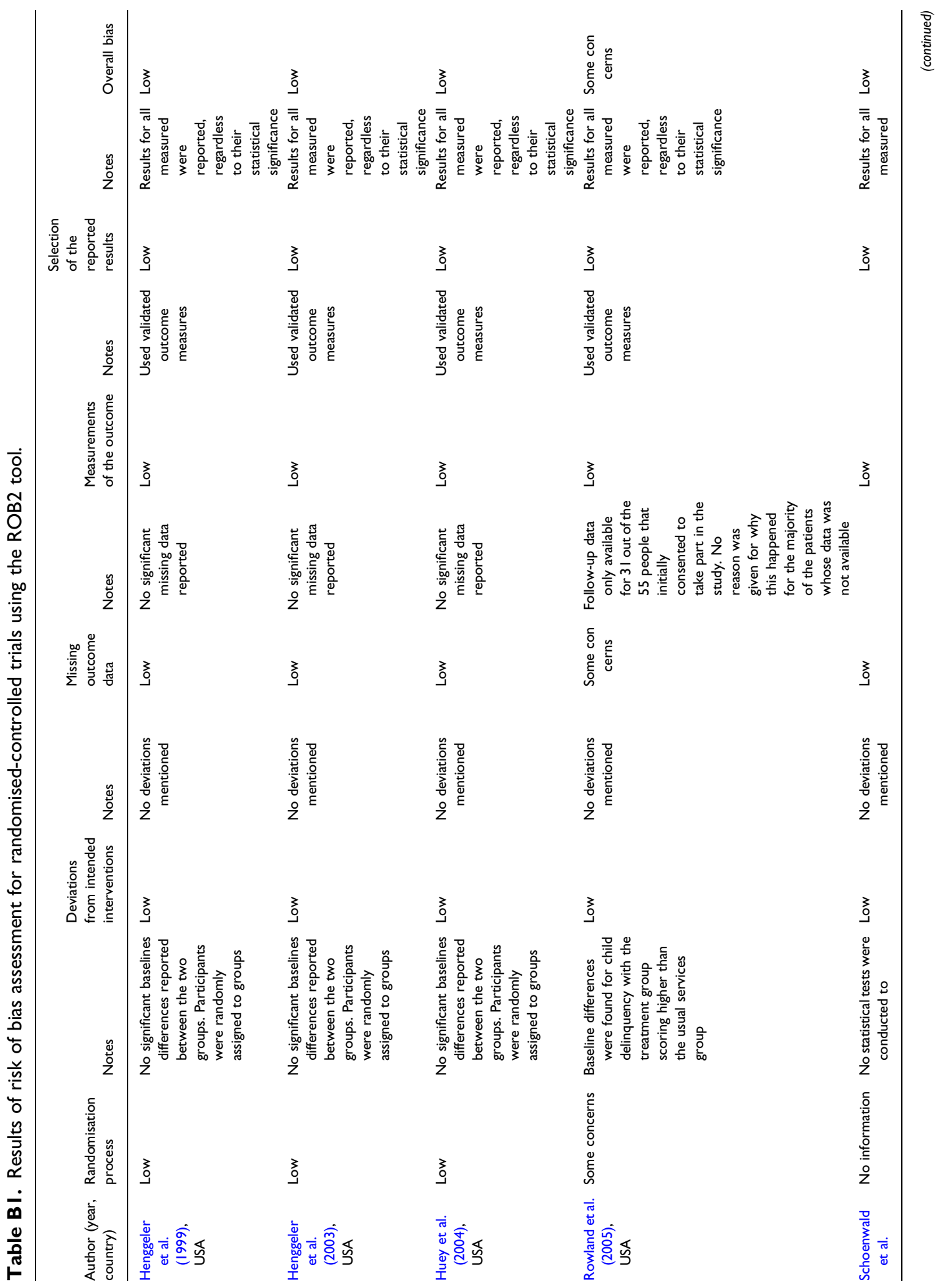




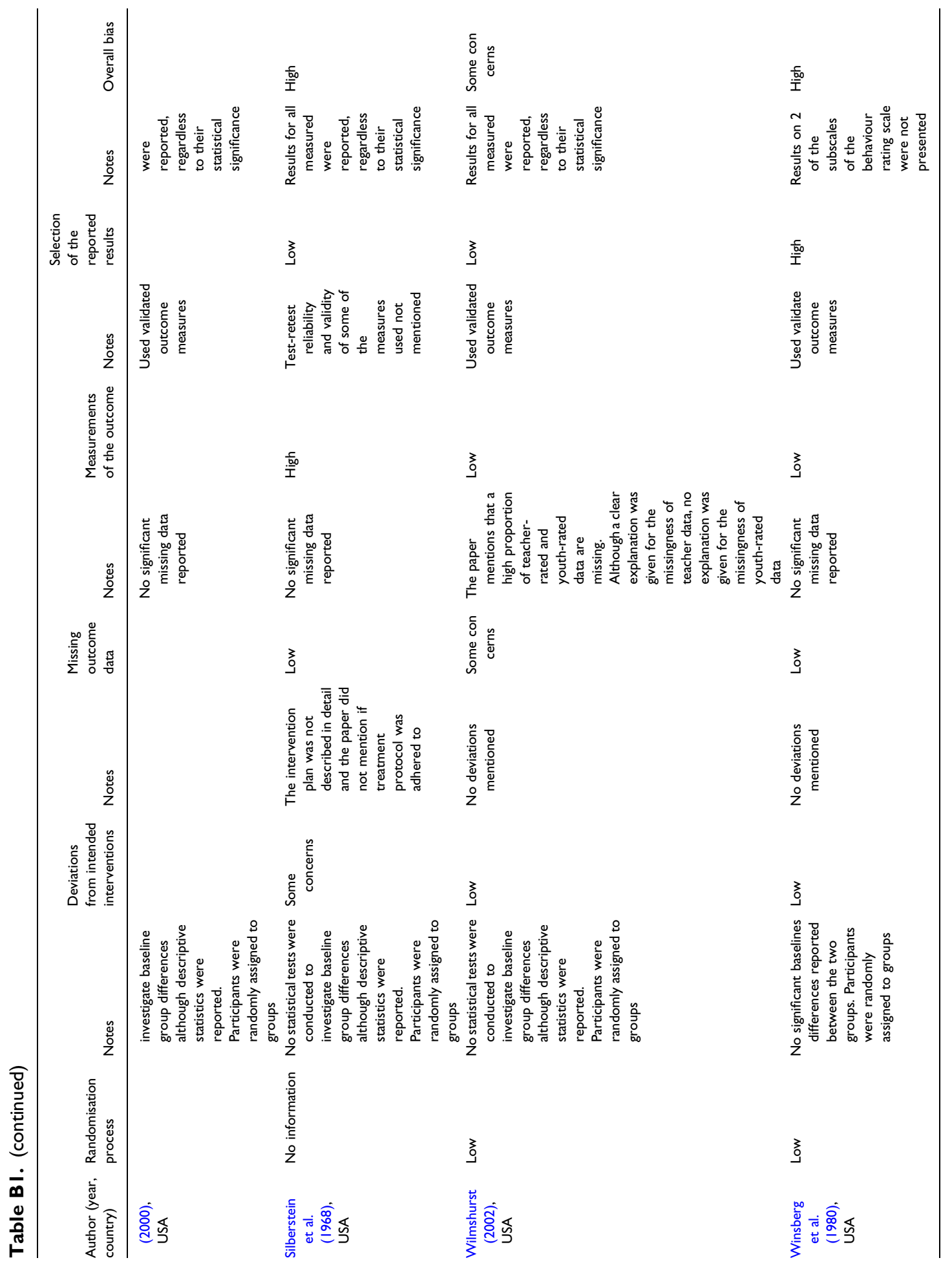




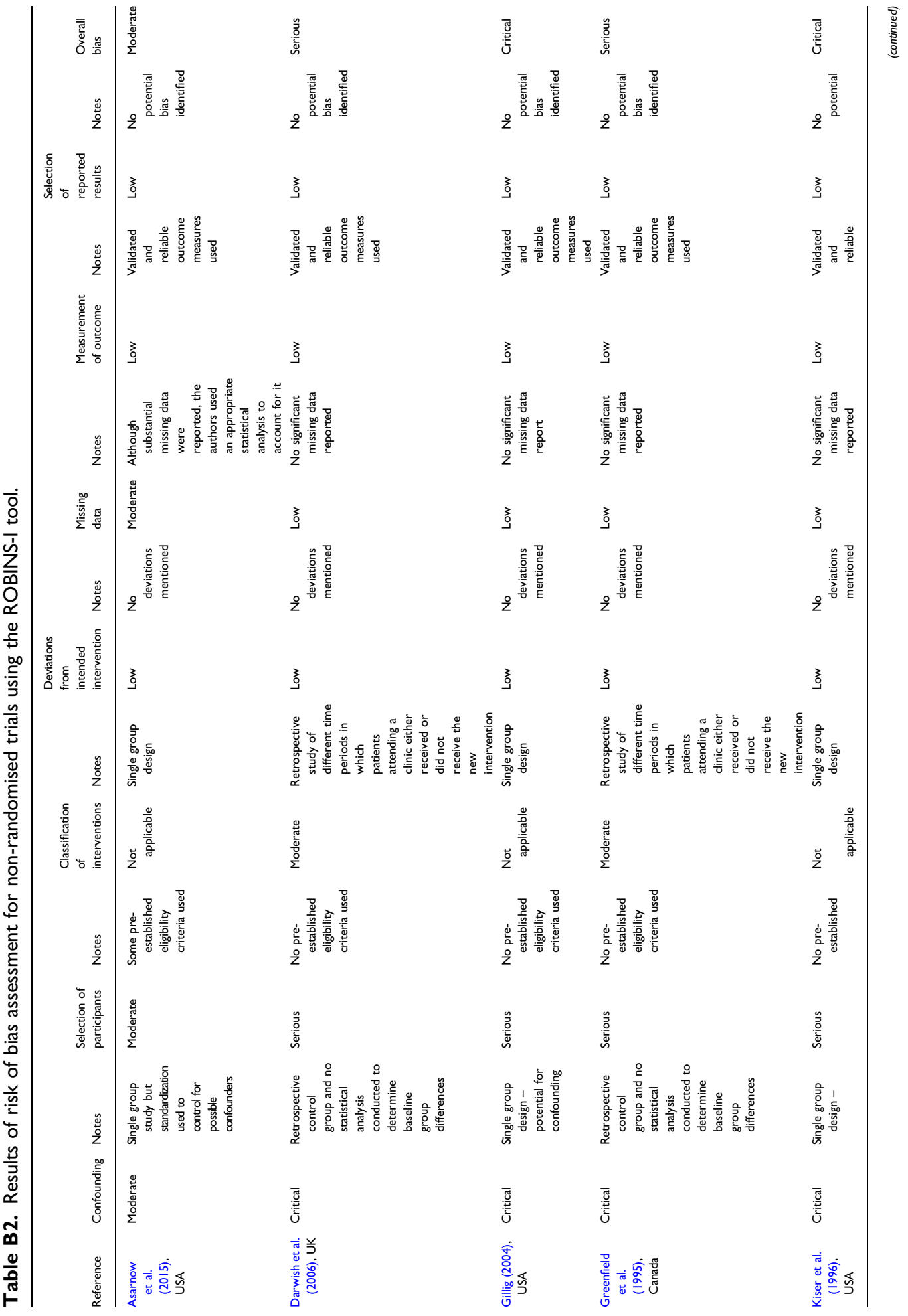




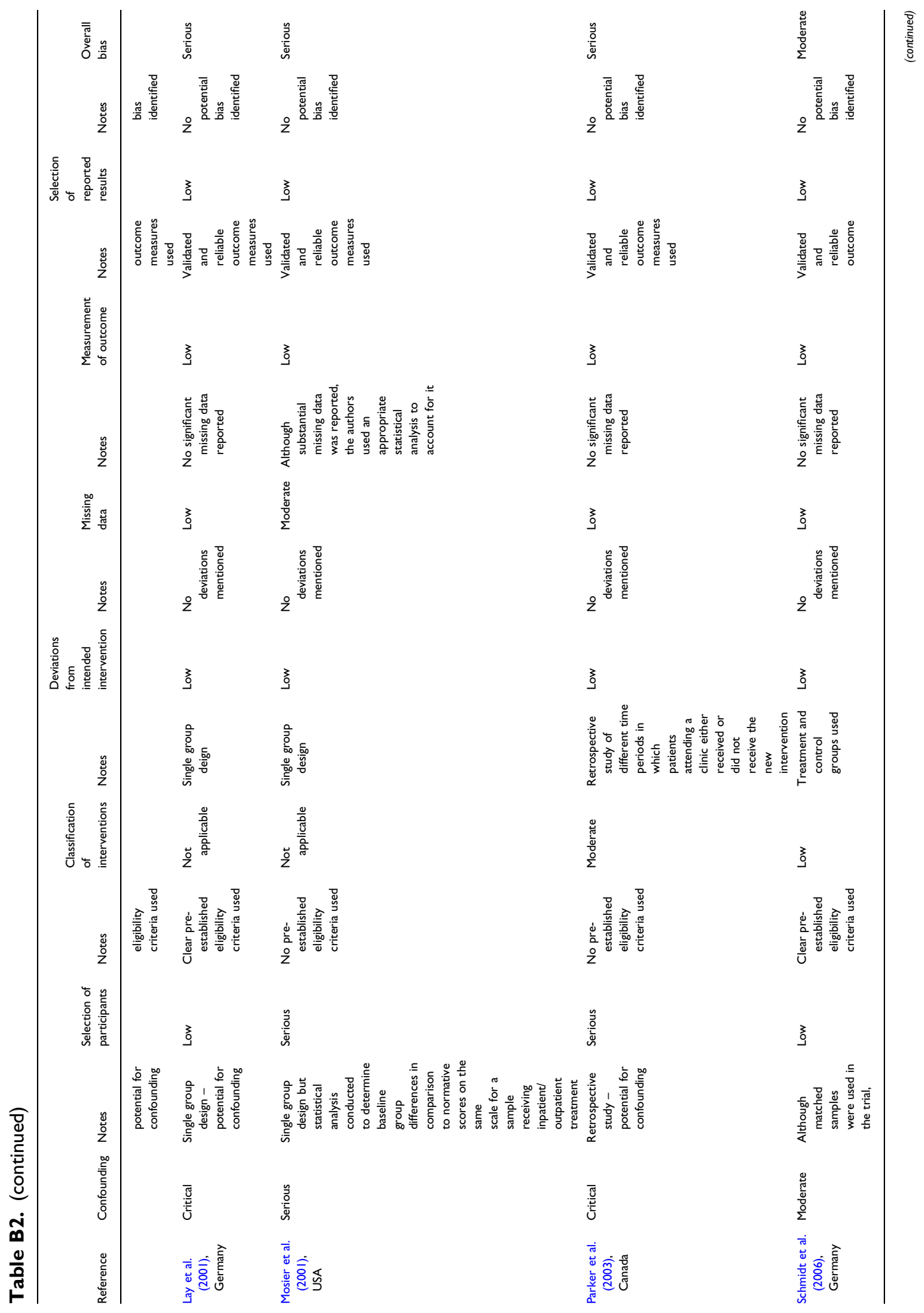




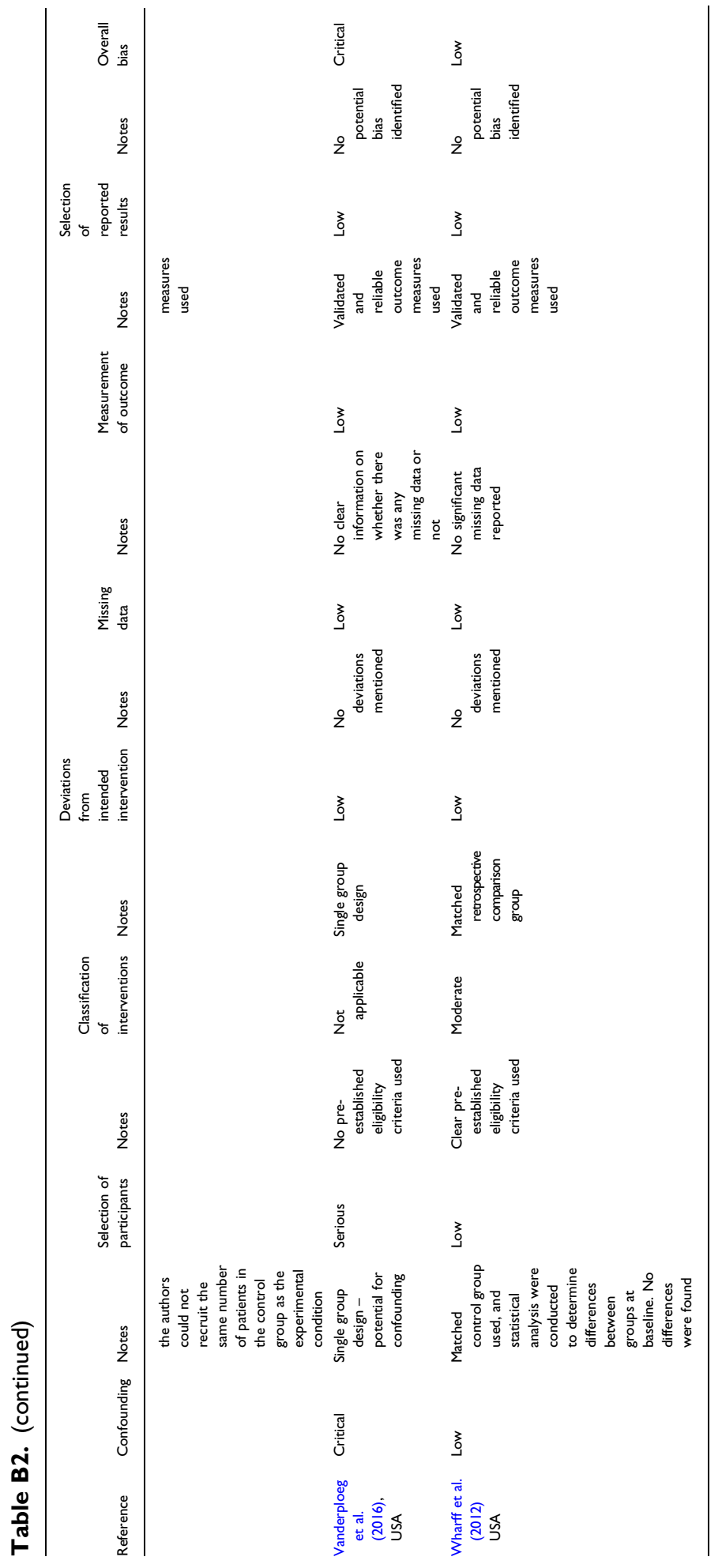




\section{Author biographies}

Denisa Clisu is a research assistant at the GOS UCL Intitute of Child Health.

Imogen Layther worked as a research assiatnt at Great Ormond Street Hospital.

Deborah Dover has over ten years experience as a Consultant in Paediatric Liaison Psychiatrist at RFH Barnet. Her special interests include quality improvement, working with physical conditions, supporting young people in crisis and suicide prevention. She is Deputy Medical Director for Barnet, Enfield and Haringey Mental Health Trust, has recently graduated as an NHSEI QSIR teaching associate and has completed the Nye Bevan programme in executive leadership.

Russell Viner is a professor of adolesent Health at the UCL GOS Institute of Child Health. He is a former president of the Royal College of Paediatrics and Child Health.

Tina Read is psychiatrist, and trust Wide Lead for CAMHS, Barnet, Enfield and Haringey Mental Health Trust.

David Cheesman has over 19 years as a board director in the NHS organisations. He is Director of Strategy \& Transformation at Barnet Enfield \& Haringey Mental Health NHS Trust - a large, complex hospital serving people in North Central London. David was previously Programme Director for Guy's \& St Thomas' (GSTT) Comprehensive Cancer Centre. Prior to joining GSTT, David was Director of Strategy at the North West London Hospitals NHS Trust, following three years at Mid Essex Hospital Services NHS Trust where he was Executive Director of Operations. He had previously been on the Board of Whipps Cross University Hospital 2002 to 2006 as Director of Acute Services and then Director of Strategy and Performance.

Sally Hodges is Clinical Chief Operating Officer of the Tavistock and Portman NHS Trust in London. Prior to taking up this role she was Director of CYAF. Before that she was Associate Clinical Director of Complex Needs in CYAF, and the Patient and Public Involvement (PPI) lead for the Trust. Sally is a Consultant Clinical Psychologist, and has been working with the Trust since May 1996, specialising in children and young people with learning and developmental disabilities. She also holds a Leadership MSc from the University of Birmingham and the NHS Leadership Academy.

Lee Hudson is a clincial associate professor at the GOS UCL Institute of Child Health and an honorary consultant paediatrician at Great Ormond Street Hospital. 